\title{
La vie de saint Alexis, Edition critique par Maurizio Perugi
}

\section{Walter Meliga}

\section{(2) OpenEdition}

1 Journals

\section{Edizione digitale}

URL: https://journals.openedition.org/studifrancesi/38856

DOI: 10.4000/studifrancesi.38856

ISSN: 2421-5856

\section{Editore}

Rosenberg \& Sellier

\section{Edizione cartacea}

Data di pubblicazione: 1 décembre 2004

Paginazione: 330

ISSN: 0039-2944

\section{Notizia bibliografica digitale}

Walter Meliga, «La vie de saint Alexis, Edition critique par Maurizio Perugi», Studi Francesi [Online], 143

(XLVIII | II) | 2004, online dal 30 novembre 2015, consultato il 19 mai 2021. URL: http://

journals.openedition.org/studifrancesi/38856 ; DOI: https://doi.org/10.4000/studifrancesi.38856

Questo documento è stato generato automaticamente il 19 mai 2021.

\section{(c) $($ i) $(9)$}

Studi Francesi è distribuita con Licenza Creative Commons Attribuzione - Non commerciale - Non opere derivate 4.0 Internazionale. 


\title{
La vie de saint Alexis, Edition critique par Maurizio Perugi
}

\author{
Walter Meliga
}

\section{NOTIZIA}

La vie de saint Alexis, Edition critique par Maurizio PERUGI, Genève, Droz ("Textes littéraires français", 529), 2000, pp. 319.

1 L'edizione è preceduta da un ampio studio introduttivo che comprende una rassegna della tradizione dei modelli latini e della formazione del testo volgare ("Stratigraphie des sources latines et du texte vernaculaire", pp. 51-100), l'esame dei luoghi generatori di varianti, esaminati alla luce del concetto di "diffrazione" (elaborato da Gianfranco Contini proprio a partire dal Saint Alexis) e di situazioni evolutive legate alla prosodia e ad aspetti linguistici particolari ("Diffraction et facteurs dynamiques", pp. 101-115), la definizione delle relazioni fra i testimoni ("Établissement du stemma”, pp. 116-134), l'analisi della lingua dell'originale ("La langue de l'original”, pp. 135-148). Il testo critico è fondato sul ms. L come "manuscrit-réceptacle" (p. 149) di varie fasi di sviluppo e stratificazione del testo, indicate in una redazione "breve", una "continuazione" contenente il racconto della sepoltura del santo e un'ulteriore addizione con la relazione dei miracoli; del manoscritto di base sono anche descritte le grafie particolari (pp. 151-157). Seguono il testo critico un ampio "Commentaire" (pp. 197-264), dove sono anche discusse le lezioni divergenti del resto della tradizione, e gli indici delle forme e dei nomi (pp. 283-315). 